\title{
Wie TARMED den medizinischen Notfall ab- schaffte, die Wirtschaftlichkeit von Arztpraxen zu Notfällen macht und schliesslich Ruhe ins Gesundheitswesen bringt
}

Mit TARMED hat man für uns einen angeblich wirtschaftlich errechneten Tarif erarbeitet, mit dem man unseren Unkosten Rechnung tragen wollte und uns entsprechend unserer Akademikerlaufbahn zu entlöhnen versprach. Mit einem Taxpunktwert von 1 Franken wohlverstanden!

Vor über 10 Jahren hat man uns in Graubünden zum Beispiel im Hinblick auf den TARMED, mit dem ja alles besser werden sollte, vertröstet und keine Tarifanpassungen mehr gewährt. Und schliesslich wurden wir mit dem Argument der Kostenneutralität etwa auf dem Stand von 1992 fixiert. Es ist schon schier unglaublich, wie wir Ärzte uns verschaukeln lassen.

Im Kanton Graubünden arbeiten wir momentan mit einem TP-Wert von 84 Rappen. Heisst dies nun, dass wir in unseren Kleinbetrieben unwirtschaftlich arbeiten und uns unserer Funktion als Geschäftsführer entheben müssten, weil wir über kurz oder lang unsere Betriebe in den Ruin führen werden?

Wenn wir mit TARMED im UVG-Bereich mit den den wirtschaftlichen Grundlagen und Bedürfnissen unserer Unternehmen entsprechenden Leistungssummen bei einem TP-Wert von 1 Franken höher liegen als im früheren UVGTarif, müsste dies also bedeuten, dass wir früher unsere Betriebe unwirtschaftlich geführt haben. Immerhin einmal ein Eingeständnis! Abgesehen davon hätte man ja sonst keinen Tarif, der eben wirtschaftlich sein muss, schaffen müssen. Wenn uns nun der TP-Wert aber wieder zurückgestuft werden sollte, würden wir also dorthin zurückgeworfen, nämlich in die ursprüngliche Unwirtschaftlichkeit. Zum Glück haben wir Ärzte schon immer mehr als landesweit üblich arbeiten dürfen, um die Wirtschaftlichkeit unserer Betriebe sichern zu können.

Betriebe wie zum Beispiel die Post erhöhen in solchen Situationen einfach ihre Preise, um wieder möglichst kostendeckend arbeiten zu können. Mit 10 bis $20 \%$ für einen alltäglichen Brief zum Beispiel sind diese nun schon wieder zufrieden. Und wir?
Und dann kommt noch der Kantönligeist dazu! Warum soll jetzt die gleiche Arbeit in Zürich oder Genf zum Beispiel einfach etwa 12 bis $16 \%$ teurer sein? Versteht das jemand auf dieser Welt? Zum Glück gibt es ja die Kostenneutralität. Neutral ist eben neutral! Ich gehe ja auch davon aus, dass für die Verwaltungskosten unserer Partner auf der Versichererseite eine Kostenneutralität wie bei den Heilungskosten eingehalten werden muss und folglich, der Kostenneutralität sei Dank, für uns alle keine Prämienerhöhungen mehr stattfinden.

Trotzdem gibt es Entwicklungen und Veränderungen, die man hinnehmen muss, auch wenn man die Kostenneutralität vereinbart hat.

Wer werden nun die Gewinner und wer die Verlierer in unserem Gesundheitsspielwesen sein? Gewinner wird es sicher geben, aber nicht unter uns Ärzten. Verlierer werden mit Bestimmtheit die Konsumenten des Gesundheitswesens sein, zu denen wir alle zusammen gehören! Ganz besonders dürfte es aber wiederum die Bevölkerung auf dem Lande, speziell in der Peripherie, treffen. Welchem Arzt wird man in Zukunft schmackhaft machen können, in einem solchen Gebiet mit viel persönlichem und zeitlichem Engagement zu praktizieren und dann erst noch zu einem schlechten und unwirtschaftlichen Tarif? Selbst dort, wo es noch viele Notfälle gibt, werden diese Einsätze und Inkonvenienzen nur noch teilweise honoriert, weil kaum ein Notfall noch als Notfall gilt, zumindest tariftechnisch nicht. Dringende Fälle gibt es im Tarif schliesslich auch nicht mehr. In der Realität im Praxisalltag sind es ja nur diese Fälle, die den Betrieb zwar stören, aber sonst unbedeutend sind, und uns doch zum Umdisponieren zwingen und unsere wartenden Patienten mit ihren vereinbarten Terminen verärgern und davonlaufen lassen. Also gibt es auch für uns keine dringlichen Fälle mehr und Notfälle nur noch selten, weil der Tarif diese auch nicht mehr vorsieht. Vielleicht sollten wir es den Schöpfern dieser De- 
finitionen verzeihen, weil sie wahrscheinlich fernab vom Geschehen nicht wissen können, was sich in einer Landpraxis tut. Es sei ihnen aber nicht verboten, Fehler einzugestehen und zu korrigieren.

Das Praktizieren auf dem Land ist jedenfalls auch längst nicht mehr so attraktiv, wie es einmal war. Wenn man in Bern von den Schwierigkeiten, für eine Landpraxis einen Nachfolger zu finden, auch noch lange nichts merkt, so hat diese Entwicklung längst schon begonnen!
Wir Ärzte schimpfen zwar mehr oder weniger laut. Dagegen etwas unternehmen tut aber kaum einer und schon gar nicht mit Solidarität. Im Gegenteil werden wir noch aus den eigenen Reihen heraus für ein paar Rappen verkauft und verraten. Anstatt zusammenzuhalten, werden wir auseinanderdividiert und dann fremdbestimmt. Einzelkämpfer werden es letztlich nicht mehr schaffen, wahrgenommen zu werden. Und so wird es wieder Ruhe geben unter den Ärzten der helvetischen Föderation. TARMED sei Dank!

Dr. med. Karl Mannhart, Präsident Hausärzte GR 